\title{
Why do patients with minor complaints choose emergency departments and does satisfaction with primary care services influence their decisions?
}

\author{
Yakup Akpinar ${ }^{1}$, Hakan Demirci ${ }^{1}$, Ersin Budak ${ }^{2}$, Ayse Karalar Baran ${ }^{1}$, Ali Candar ${ }^{1}$ and Gokhan Ocakoglu ${ }^{3}$ \\ ${ }^{1}$ Department of Family Medicine, University of Health Sciences Bursa Yuksek Ihtisas Training and Research Hospital, \\ Bursa, Turkey \\ ${ }^{2}$ Department of Psychology, University of Health Sciences Bursa Yuksek Ihtisas Training and Research Hospital, \\ Bursa, Turkey \\ ${ }^{3}$ Department of Biostatistics, Uludag University, Bursa, Turkey
}

\begin{abstract}
Aim: To identify the reasons why patients with minor complaints choose emergency departments (EDs) as a first contact of care and whether dissatisfaction with primary care services influences their decisions. Methods: In this study, a self-completed survey called EUROPEP was given to 535 outpatients who were admitted to the XXXXX Hospital in Bursa and examined in the green zone in July 2015. Patients were asked about their complaints and why they preferred EDs as a first contact of care. Results: EDs were the first contact of care in $87.8 \%$ of cases. In all, $9 \%$ of patients registered to family physicians who were working outside the city of Bursa. There was no relationship between patient satisfaction and the number of previous visits to EDs in last 12 months $(P=0.09)$. The main reasons for admitting to the emergency services were feeling excessive pain $(20.4 \%)$, perception of urgency $(14.5 \%)$ and that the family doctor services were closed outside working hours $(13.2 \%)$. The mean patient satisfaction with family practice offices was calculated to be $68.1 \%$. Conclusions: The frequency of admission to EDs as a first contact of care was extremely high in the absence of a referral system. Patients who did not have family doctors in the settlement where they live put an extra burden on the EDs. Overall, patient satisfaction with their GPs did not influence the number of visits to EDs but accessibility remains a big challenge.
\end{abstract}

Key words: continuity of care; emergency medicine/urgent care; family health; primary care; quality of care; referral system

Received 9 March 2017; revised 13 November 2017; accepted 19 November 2017; first published online 18 December 2017

\section{Introduction}

Countries having stronger primary care generally have healthier people (Starsfield et al., 2005). Though health policies and practices are different worldwide, family medicine constitutes the basic element of health services. A strong primary care

Correspondence to: Associate Professor Hakan Demirci, Department of Family Medicine, Bursa Yuksek Ihtisas Training and Research Hospital, Yildirim, Bursa, 16260, Turkey. Email: drhakandemirci@hotmail.com enables a cheaper healthcare service that is more easily accessible and with better satisfaction (Kringos et al., 2013). Research has shown that family doctors can deliver solutions for more than $90 \%$ of the problems of their patients without referral (Grumbach et al., 1999; Ustu and Ugurlu, 2015).

In Turkey, following pilot schemes, family medicine has begun to be applied throughout the country since 2010 (Akman, 2014). The determinants of medical service quality in Turkey have been affected positively with the family practice system (Hone et al., 2017). A significant decrease 
in the mortality rate of mothers and babies under five attracts notice, which is attributed to health reforms, including Family Medicine, that have been implemented (Jelamschi and De Ver Dye, 2009; Turkish Ministry of Health, 2012-2014).

While there is a remarkable improvement in health outcomes, an increased number of visits to Emergency Departments (EDs) have come to the forefront as one of the most important problems in the Turkish healthcare system (Ulker et al., 2017). The best example of this situation is that there are more visits to EDs annually than the total population of Turkey. The data of the Republic of Turkey, Ministry of Health, reports that there were 100081171 visits to the EDs in 2013 (Bektemur et al., 2015). For comparison, in the United States overall, there are 42 ED visits per 100 persons annually (Dyrda, 2016) and ED attendance was more than 400 per 1000 persons in the United Kingdom in 2015 (Baker, 2017).

There may be many explanations for high rates of ED admissions in Turkey, for example absence of an obligatory referral system is one of them. A referral system is obligatory in half of the European countries and self-referrals are subject to financial implications in some countries (Kringos et al., 2013). In seven European countries, including Turkey, self-referral is free.

The triage system gives priority to patients according to the urgency of the situation. In the red zone, patients should be quickly treated while in the green zone patients can wait for a longer time, who often suffer from illnesses that could be solved in family medicine offices (Durand et al., 2011). To get a more efficient emergency service, non-urgent cases could be evaluated by family physicians. In the United Kingdom, for example, redirection of patients from the green zone to GPs after a preliminary examination in triage is an effort towards a solution of the problem (Bentley et al., 2017).

In the present study, the aim was to identify the reasons why patients with minor complaints choose EDs as a first contact of care, instead of primary care, and whether dissatisfaction with primary care services influences their decisions.

\section{Methods}

\section{Participants}

The study was designed as a descriptive study. In total, 840 patients who were admitted to the
Bursa Yuksek Ihtisas Training and Research Hospital ED in July 2015, who undertook consultation in the green zone and who were recorded as outpatients participated in the study. In the same period, 22538 patients in total were consulted in the green zone. The patients involved in the study $(n=840)$ consisted of $0.37 \%$ of these patients. A family medicine residency trainee working in the ED of the hospital in that period, in out of office hours, invited every eligible patient he examined to participate in the study. During the study, he was the single trainee working in the green zone of the hospital. The criteria for involvement in the study were patients over 18 years old, outpatients applying to the green zone, Turkish citizenship and voluntary involvement acceptance. Patients who had not visited their primary care doctor in the last 12 months were excluded from the study. A written informed consent was obtained from the participants.

\section{Materials}

This research used a questionnaire in order to identify socio-demographic characteristics. In addition to this, the EUROPEP (Patients Evaluate General/Family Practice) scale was used which measured the satisfaction of patients with the primary care services. Validation of the scale was obtained by Akturk et al. (2002). EUROPEP is a scale prepared by EQUIP (European Working Party on Quality in General Practice) that is used to evaluate family doctors and family health centers in more than 20 European countries. The scale is a selfcompleted survey and consists of five dimensions and 23 questions. These are doctor-patient relationship (questions 1-6), medical care (questions 711), information and support (questions 12-15), health service organization (questions 16-17) and accessibility (questions 18-23). Patients were asked to answer questions on a five-point scale ranging from $1=$ poor to $5=$ excellent, and all the items were scored in the same direction (Vedsted et al., 2008).

\section{Statistical analysis}

Categorical data were presented with frequency and related percentage values while continuous data were expressed as median (minimum: maximum). The relationship between patient satisfaction and the frequency of visits to EDs was 
evaluated by Mann-Whitney test. The correlation between the frequency of visits to the family doctor and EDs was evaluated by Spearman correlation coefficient. Patient mean satisfaction scores were divided into four groups according to quartiles and percentile values were calculated. Evaluation of the data was done using IBM SPSS 20.0 (IBM Corp. Released 2011. IBM SPSS Statistics for Windows, Version 20.0, IBM Corp., Armonk, NY) Statistical significance was set at $P<0.05$.

\section{Results}

In total, 53 patients who were either visitors or who recently moved to the city and their family doctors were outside of Bursa were not included in the study; 179 patients who had not visited their family doctor in the last 12 months were also excluded. In total, 608 patients were invited into the study and 535 agreed to participate in the study (response rate was $87.9 \%$ ); 26 patients who could not fill out the EUROPEP questionnaire were excluded from the research (Figure1). Data analysis was therefore performed with the results of 509 participants (Table 1 ).

Of the total patients, $319(71.7 \%)$ stated that their complication started within the previous three days. Overall, 446 (87.8\%) of the patients' first contact of care was in EDs (Table 2). The most frequently seen complaints leading to an ED visit were excessive pain $(20.4 \%)$, perceived urgency $(14.5 \%)$ and that EDs were available $24 \mathrm{~h}$ a day $(13.2 \%)$ (Table 3$)$. When patients' primary complaints were examined: 175 patients $(34.4 \%)$ had flu-like symptoms (fever and fatigue), 73 patients $(14.3 \%)$ had chronic pain, 49 patients $(9.6 \%)$ had dyspeptic complaints, 37 patients $(7.3 \%)$ had migraine headache, 31 patients $(6.1 \%)$ were referred to the EDs due to sore throat, 28 patients $(5.5 \%)$ for skin problems and 116 patients $(22.8 \%)$ for other complaints.

Analysis of the EUROPEP scale revealed that satisfaction with the family practice unit was $68.1 \%$. The most satisfactory situation according to the patients was that their family doctor listens to them and performs a physical examination $(76.8 \%)$. On the other hand, the most dissatisfactory situation for patients was that doctors $(29.1 \%)$ and family medicine clinics (43.4\%) cannot be reached by phone (Table 4).
Total response rate to the EUROPEP questions was $93.16 \%$. And, the response rates for items varied between 98.82 and $74.07 \%$ (Table 5 and Figure 2). The item 'making you feel you had time during consultation' had the highest response rate (98.82), whereas the item 'keeping your records and data confidential' had the lowest response rate (74.07\%).

When the patients were divided into quartile groups according to their average satisfaction scores, there was no statistically significant difference between the groups in terms of the frequency of ED visits in the last 12 months $(P=0.09)$. It was found that there was a weak positive correlation between visits of patients to family doctors and to EDs $(P<0.001 ; r=0.29)$. The internal reliability coefficient on the EUROPEP scale was 0.97 as a Cronbach's $\alpha$ value (Figure 2).

\section{Discussion}

According to the results of this study, of the patients examined in the green zone, the main reasons for admission to EDs were feeling pain, the perception of urgency and that family doctor services were closed outside working hours. The large majority of the patients $(71.7 \%)$ stated that their symptoms started within the last three days. In the absence of a referral system, easy accessibility to hospitals was the main reason why patients bypassed family doctors and came to EDs.

The duration of patient complaints was longer than that found in other studies. It was found that visits to EDs within the first $24 \mathrm{~h}$ of complications were 77\% (Bianco et al., 2003; Durand et al., 2011). In a study performed in Turkey, the rate of visiting within the first $24 \mathrm{~h}$ was $73 \%$ (Akturk et al., 2002). In the current study, we found that visits within $24 \mathrm{~h}$ of complications occurring were $32.1 \%$ and within the first three days of complications was $71.7 \%$. These results show that especially acute cases prefer EDs. As previous studies included not only the green zone but the whole EDs, the percentage of visits within the first $24 \mathrm{~h}$ was higher. In this study, only those patients who were examined in the green zone were included. In the green zone, patients were at a lower risk of a life threatening condition. The cases were mostly composed of patients with flu-like symptoms, chronic pain and dyspeptic complaints. Patients can be 


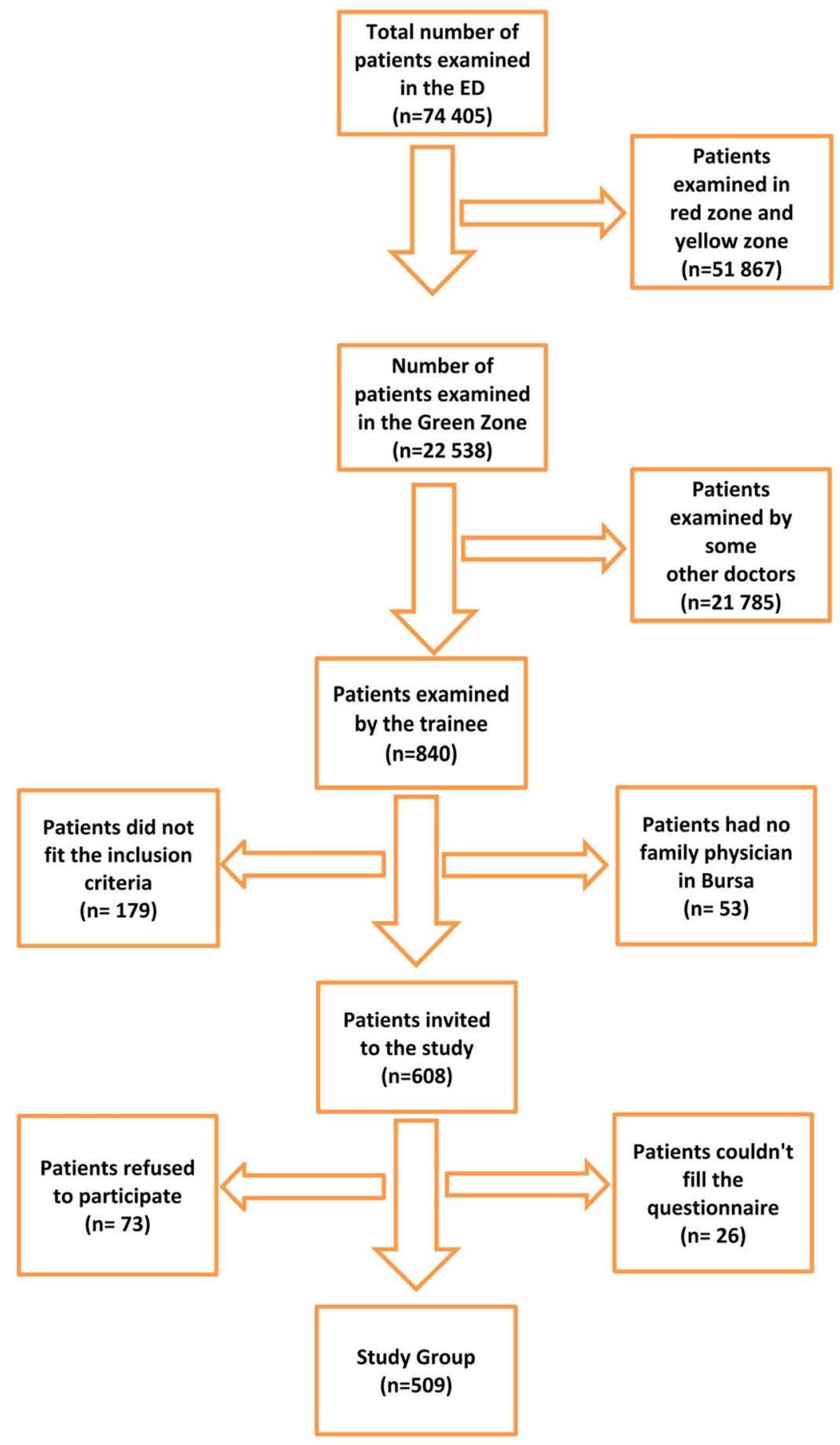

Figure 1 Patient inclusion flowchart 
Table 1 Socio-demographic features of the patients

\begin{tabular}{|c|c|c|}
\hline & Number of patients & Percent (\%) \\
\hline \multicolumn{3}{|l|}{ Gender } \\
\hline Male & 216 & 42.4 \\
\hline Female & 293 & 57.6 \\
\hline \multicolumn{3}{|l|}{ Age groups } \\
\hline$<20$ & 39 & 7.7 \\
\hline 20-29 & 161 & 31.6 \\
\hline $30-39$ & 147 & 28.9 \\
\hline $40-49$ & 82 & 16.1 \\
\hline $50-59$ & 50 & 9.8 \\
\hline$\geqslant 60$ & 30 & 5.9 \\
\hline \multicolumn{3}{|l|}{ Marital status } \\
\hline Married & 320 & 69.1 \\
\hline Single & 124 & 26.8 \\
\hline Divorced & 17 & 3.7 \\
\hline \multicolumn{3}{|l|}{ Education level } \\
\hline Illiterate & 35 & 6.7 \\
\hline Primary school & 270 & 59.3 \\
\hline High school & 92 & 20.2 \\
\hline College & 58 & 12.7 \\
\hline \multicolumn{3}{|l|}{ Income/month } \\
\hline$<300$ USD & 217 & 57.7 \\
\hline $300-600$ USD & 134 & 35.6 \\
\hline$>600$ USD & 25 & 6.6 \\
\hline \multicolumn{3}{|l|}{ Employment status } \\
\hline Unemployed & 69 & 15.1 \\
\hline Housewife & 141 & 30.9 \\
\hline Worker & 167 & 36.6 \\
\hline Officer & 14 & 3.1 \\
\hline Student & 35 & 7.7 \\
\hline Professional worker & 13 & 2.9 \\
\hline Retired & 17 & 3.7 \\
\hline
\end{tabular}

Table 2 Characteristics of complaints of the patients

\begin{tabular}{|c|c|c|}
\hline & $\begin{array}{l}\text { Number of } \\
\text { patients }\end{array}$ & $\begin{array}{l}\text { Percent } \\
(\%)\end{array}$ \\
\hline \multicolumn{3}{|c|}{ Time period of the complaints } \\
\hline$<24 \mathrm{~h}$ & 143 & 32.1 \\
\hline $1-3$ days & 176 & 39.6 \\
\hline 4-6 days & 51 & 11.5 \\
\hline 7-90 days & 45 & 10.1 \\
\hline$>90$ days & 30 & 6.7 \\
\hline \multicolumn{3}{|c|}{$\begin{array}{l}\text { Visited another doctor with the } \\
\text { same complaint }\end{array}$} \\
\hline Yes & 62 & 12.2 \\
\hline No & 446 & 87.8 \\
\hline \multicolumn{3}{|c|}{$\begin{array}{l}\text { Already using a medication for the } \\
\text { same complaint }\end{array}$} \\
\hline Yes & 133 & 30.6 \\
\hline No & 302 & 69.4 \\
\hline \multicolumn{3}{|c|}{$\begin{array}{l}\text { Knowing the name of the family } \\
\text { doctor }\end{array}$} \\
\hline Yes & 348 & 89 \\
\hline No & 43 & 11 \\
\hline
\end{tabular}

Table 3 The reason why patients prefer emergency services

\begin{tabular}{lll}
\hline & $\begin{array}{l}\text { Number of } \\
\text { patients }\end{array}$ & $\begin{array}{l}\text { Percent } \\
(\%)\end{array}$ \\
\hline Feeling excessive pain & 104 & 20.4 \\
Thinking it is an emergency & 74 & 14.5 \\
Out of working time for GPs & 67 & 13.2 \\
Anxiety & 37 & 7.3 \\
Rapid consultation and & 44 & 8.6 \\
$\quad$ treatment & & \\
Better treatment & 22 & 4.3 \\
Near to me & 16 & 3.1 \\
Better testing opportunity & 12 & 2.4 \\
No answer & 132 & 25.9 \\
\hline
\end{tabular}

educated how to manage these symptoms by increasing their health literacy.

It was reported that $72 \%$ of the ED applicants thought that their complications were medium or highly serious and $59 \%$ of them stated that their complications required immediate attention and treatment (Lucas and Sanford, 1998). In another study investigating the reason why patients choose EDs, $85.8 \%$ of the patients came because of 'pain' and $60.5 \%$ of the patients were admitted to EDs thinking that their problem should be managed urgently (Durand et al., 2011). Similarly, in other studies patients reported that they came to EDs because they perceived urgent need (Shah and Shah, 1994; Lucas and Sanford, 1998; Bianco et al., 2003). Beland et al. showed that patients living near to the ED visit those departments more frequently and real emergency cases come to those departments from long distances (Beland et al., 1998). In the present study, the reasons for visiting EDs were 'feeling so much pain' (backache, headache, migraine patients, pain due to trauma and pain due to infection) $20.4 \%$, 'thinking it is an emergency situation' $14.5 \%$, 'EDs are open also outside work hours' $13.2 \%$, 'fast examination and treatment at EDs' $8.6 \%$, 'better intervention' $4.3 \%$, 'near home' $3.1 \%$ and 'the opportunity for analysis and tests' $2.4 \%$. The present study is an example of what will happen with a self-referral system. In a self-referral system, hospital admissions originating from expectations (eg, faster and better service) were as much as admissions directed by serious symptoms.

In this study, the rate of admission to EDs as the first point of application was determined as $87.8 \%$, which was because of the free self-referral system 
Table 4 Patient satisfaction with family physicians

\begin{tabular}{|c|c|c|c|c|}
\hline & Satisfied & $\begin{array}{l}\text { Percent } \\
(\%)\end{array}$ & $\begin{array}{l}\text { Not } \\
\text { satisfied }\end{array}$ & $\begin{array}{l}\text { Percent } \\
(\%)\end{array}$ \\
\hline 1. Making you feel you had time during consultation & 337 & 66.2 & 48 & 9.4 \\
\hline 2. Interest in your personal situation & 337 & 74.1 & 33 & 6.5 \\
\hline 3. Making it easy for you to tell him or her about your problem & 373 & 73.3 & 34 & 6.7 \\
\hline 4. Involving you in decisions about your medical care & 338 & 66.4 & 35 & 6.9 \\
\hline 5. Listening to you & 402 & 79 & 27 & 5.3 \\
\hline 6. Keeping your records and data confidential & 311 & 61.1 & 15 & 2.9 \\
\hline 7. Quick relief of your symptoms & 322 & 63.3 & 36 & 7.1 \\
\hline $\begin{array}{l}\text { 8. Helping you to feel well so that you can perform your normal daily } \\
\text { activities }\end{array}$ & 345 & 67.8 & 31 & 6.1 \\
\hline 9. Thoroughness & 387 & 76 & 30 & 5.9 \\
\hline 10. Physical examination & 391 & 76.8 & 19 & 3.7 \\
\hline $\begin{array}{l}\text { 11. Offering services for preventing diseases (eg, screening and } \\
\text { immunizations) }\end{array}$ & 353 & 69.4 & 34 & 6.7 \\
\hline 12. Explaining the purpose of tests and treatments & 341 & 67 & 31 & 6.1 \\
\hline $\begin{array}{l}\text { 13. Telling you what you wanted to know about your symptoms and/or } \\
\text { illness }\end{array}$ & 359 & 70.5 & 28 & 5.5 \\
\hline $\begin{array}{l}\text { 14. Helping you deal with emotional problems related to your health } \\
\text { status }\end{array}$ & 321 & 63.1 & 44 & 8.6 \\
\hline 15. Helping understand the importance of following his or her advice & 353 & 69.4 & 31 & 6.1 \\
\hline 16. Knowing what $s /$ he had done or told you during contacts & 326 & 64 & 44 & 8.6 \\
\hline 17. Preparing you for what to expect from specialist or hospital care & 318 & 62.5 & 34 & 6.7 \\
\hline 18. The helpfulness of the practice staff (other than the doctor) & 320 & 62.9 & 57 & 11.2 \\
\hline 19. Getting an appointment to suit you & 307 & 60.3 & 68 & 13.4 \\
\hline 20. Getting through to the practice on the telephone & 221 & 43.4 & 140 & \\
\hline 21. Being able to speak to the general practitioner on the telephone & 148 & 29.1 & 210 & 41.3 \\
\hline 22. Waiting time in the waiting room & 241 & 47.3 & 111 & 21.8 \\
\hline 23. Providing quick services for urgent health problems & 277 & 54.4 & 85 & 16.7 \\
\hline
\end{tabular}

Satisfied patient corresponds to ones who marked the item as good or very good. Not satisfied patient corresponds to ones who marked the item as 'bad' and 'very bad'.

in Turkey. There are few countries in Europe that use a no-referral system. A referral system helps to triage patients in primary care, which is known as 'gate keeping' in healthcare facilities. If selfreferral application persists, then we should educate people for better use of the system. Apart from this, $9 \%$ of patient family physicians who were outside of the Bursa province may have contributed to this increase. In one study, it was reported that family physicians were not eager to deal with guest patients (Akman, 2014). If so, it would not be surprising that the patients referred themselves to hospitals. Guest patients were an extra burden on the ED, which must be solved by registering the patients as soon as possible when they move. Another reason for excessive ED applications was shown to be that family physicians could not be reached outside of working hours, similar to the results obtained in previous studies (Huntley et al., 2014). Only EDs have healthcare workers where patients can receive health services outside of working hours. The 24-h primary care topic has been discussed extensively, but a sufficient number of qualified healthcare workers are needed for such an application.

In the current study, patient satisfaction with family doctors was lower when compared with previous studies performed at primary care facilities, but comparisons should be made with caution since patient profiles were different. In a previous study, patient satisfaction with primary care services was found to be $88.3 \%$ in Turkey (Akturk et al., 2015). In the study of Mete et al., which was performed in Malatya, $80.7 \%$ of the participants stated that they were satisfied/very satisfied with the family medicine system (Mete et al., 2015). In the study, Bostan et al. performed in Gumushane, the general satisfaction level was $87.5 \%$ (Bostan and Havvatoglu, 2014). In the current study, satisfaction of the patients with their family 
Table 5 The number of participants who did not answer any particular question

\begin{tabular}{|c|c|c|}
\hline & Number of participants & Percent (\%) \\
\hline 1. Making you feel you had time during consultation & 6 & 1.18 \\
\hline 2. Interest in your personal situation & 9 & 1.77 \\
\hline 3. Making it easy for you to tell him or her about your problem & 10 & 1.96 \\
\hline 4. Involving you in decisions about your medical care & 32 & 6.29 \\
\hline 5. Listening to you & 15 & 2.95 \\
\hline 6. Keeping your records and data confidential & 132 & 25.93 \\
\hline 7. Quick relief of your symptoms & 25 & 4.91 \\
\hline 8. Helping you to feel well so that you can perform your normal daily activities & 25 & 4.91 \\
\hline 9. Thoroughness & 11 & 2.16 \\
\hline 10. Physical examination & 21 & 4.13 \\
\hline 11. Offering services for preventing diseases (eg, screening and immunizations) & 25 & 4.91 \\
\hline 12. Explaining the purpose of tests and treatments & 36 & 7.07 \\
\hline 13. Telling you what you wanted to know about your symptoms and/or illness & 20 & 3.93 \\
\hline 14. Helping you deal with emotional problems related to your health status & 41 & 8.06 \\
\hline 15. Helping understand the importance of following his or her advice & 26 & 5.11 \\
\hline 16. Knowing what s/he had done or told you during contacts & 39 & 7.66 \\
\hline 17. Preparing you for what to expect from specialist or hospital care & 51 & 10.02 \\
\hline 18. The helpfulness of the practice staff (other than the doctor) & 35 & 6.88 \\
\hline 19. Getting an appointment to suit you & 33 & 6.48 \\
\hline 20. Getting through to the practice on the telephone & 62 & 12.18 \\
\hline 21. Being able to speak to the general practitioner on the telephone & 80 & 15.72 \\
\hline 22. Waiting time in the waiting room & 29 & 5.70 \\
\hline 23. Providing quick services for urgent health problems & 37 & 7.27 \\
\hline
\end{tabular}

doctors was $68.1 \%$. They mostly suffered from lack of accessibility to their primary care office, either for visiting or by telephone contact. Inaccessibility is the predominant problem not only for the participants in the present study but is a common health problem for almost every country. Of course, it can be reinforced by increasing the number of qualified healthcare workers. But, to what extent? It is not possible to have a doctor on every block at every time. However, for example, efforts to improve health literacy in the public may help people to better benefit from health facilities. Family physicians should focus on this issue and should try to educate patients on health.

Many studies show that frequent users of EDs are also frequent visitors to family doctors (Ovens and Chan, 2001; Benjamin et al., 2002; Chan and Ovens, 2002; Carrière, 2004). This situation could be explained by people having many co-morbid diseases. Additionally, it was found that frequent users of EDs have a high risk of chronic diseases and a high mortality rate (Sun et al., 2003; Hunt et al., 2006). In the present study, a relationship between the frequency of family doctor visits and the frequency of ED visits was found. Family physicians should carefully evaluate the history of frequent hospital/primary healthcare visits in terms of co-morbidities. For example, frequent visits due to throat infection may be associated with new onset diabetes mellitus. Similarly, infections that do not heal in an average time interval can be a sign of cancer or diabetes mellitus.

\section{Limitations of the study}

It would have been better to have a control group in the present study, since the EUROPEP questionnaire has no cut-off value and so classification of a person as satisfied or not satisfied was problematic. Instead of personal satisfaction, evaluation of general satisfaction was subject to discussion in the present study. It would have been better to compare satisfaction obtained from patients admitted to EDs with those who were not admitted as a case control study.

In conclusion, this study is the first to evaluate satisfaction with family doctors of patients visiting EDs using the EUROPEP scale. In this sampling, about one-third of the participants were not satisfied with their family practice services but satisfaction was not associated with frequent $E D$ visits. In total, $9 \%$ of the patients invited to participate were not registered with a family physician working in the 


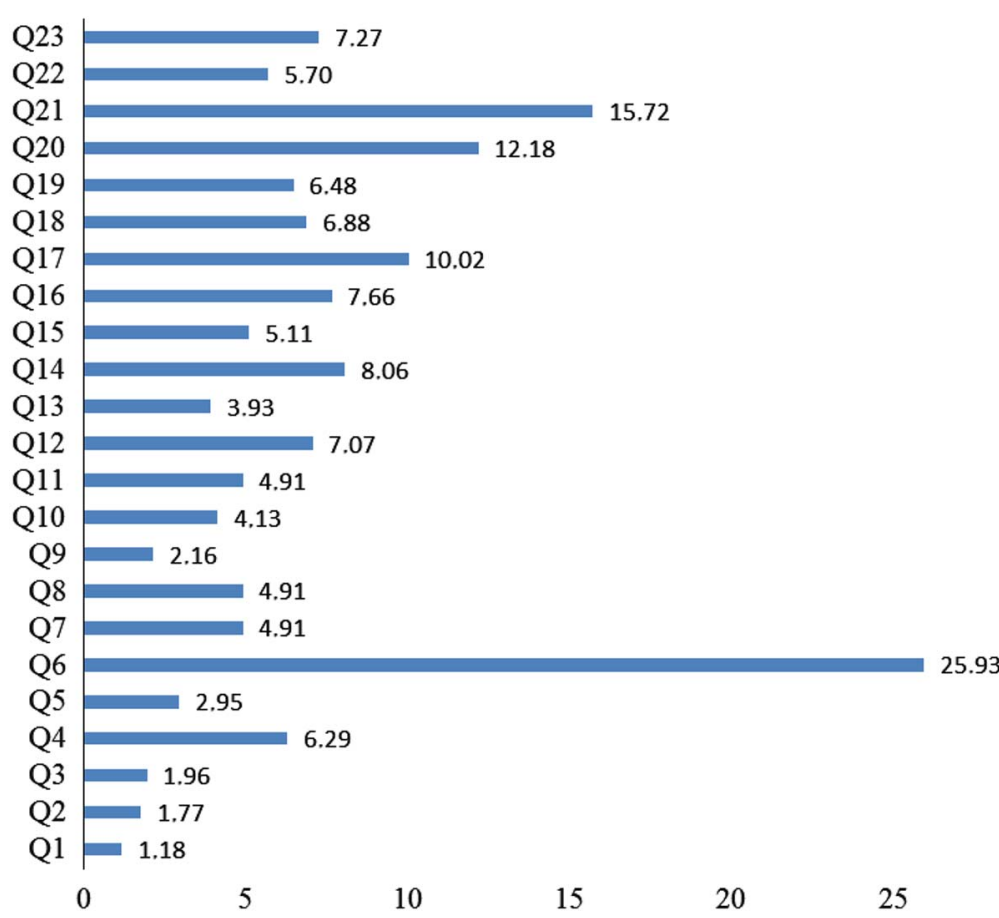

30

Figure 2 Distribution of unanswered questions. Q1: Making you feel you had time during consultation; Q2: Interest in your personal situation; Q3: Making it easy for you to tell him or her about your problem; Q4: Involving you in decisions about your medical care; Q5: Listening to you; Q6: Keeping your records and data confidential; Q7: Quick relief of your symptoms; Q8. Helping you to feel well so that you can perform your normal daily activities; 09: Thoroughness; Q10: Physical examination; Q11: Offering services for preventing diseases (eg, screening and immunizations); Q12: Explaining the purpose of tests and treatments; 013: Telling you what you wanted to know about your symptoms and/or illness; Q14: Helping you deal with emotional problems related to your health status; Q15: Helping understand the importance of following his or her advice; Q16: Knowing what s/he had done or told you during contacts; Q17: Preparing you for what to expect from specialist or hospital care; Q18: The helpfulness of the practice staff (other than the doctor); Q19: Getting an appointment to suit you; Q20: Getting through to the practice on the telephone; Q21: Being able to speak to the general practitioner on the telephone; Q22: Waiting time in the waiting room; Q23: Providing quick services for urgent health problems

city and this puts extra burden on EDs. In the case of migration, family medicine records should be rapidly transferred to the new location. Frequent admissions should be carefully evaluated in terms of serious co-morbidities. Trials to improve public health literacy can be suggested to reduce non-urgent visits, especially in countries where self-referral is free.

\section{Acknowledgments}

The authors thank Mrs. Nazli Demirci (Philologist) for her contribution to the study.

\section{Financial Support}

None.

\section{Conflicts of Interest}

None.

\section{Ethical Standard}

The Ethics Committee of the Bursa Yuksek Ihtisas Training and Research Hospital approved the study.

\section{References}

Akman, M. 2014: Strength of primarycare in Turkey. Turkish Journal of Family Practice 18, 70-78.

Akturk, Z., Atesoglu, D. and Ciftci, E. 2015: Patient satisfaction with family practice in Turkey: three-year trend from 2010 to 2012. European Journal of General Practice 21, 238-45. 
Akturk, Z., Dagdeviren, N., Sahin, E.M., Ozer, C., Yaman, H., Goktaş, O., Filiz, T.M., Topsever, P., Organer, E., Aydin, S., Yaris, F. and Maras, I. 2002: Patients evaluate their doctors, EUROPEP Scale. Journal of DEU Medical School 3, 153-60.

Baker, C. 2017: Accident and emergency statistics: demand, performance and pressure. Retrieved 31 October 2017 from http://researchbriefings.parliament.uk/ResearchBriefing/ Summary/SN06964.

Bektemur, G., Osmanbeyoglu, N. and Cander, B., 2015: Acil Hizmetler Raporu. Eurasian Journal of Emergency Medicine 14, 1-52.

Beland, F., Lemay, A. and Boucher, M. 1998: Pattern of visits to hospital-based emergency rooms. Social Science \& Medicine 47 (2), 165-79.

Bentley, J.A., Thakore, S., Morrison, W. and Wang, W. 2017: Emergency department redirection to primary care: a prospective evaluation of practice. Scottish Medical Journal 62 (1), 2-10.

Bianco, A., Pileggi, C. and Angelillo, I.F. 2003: Non-urgent visits to a hospital emergency department in Italy. Journal of the Royal Institute of Public Health 117, 250-55.

Bostan, S. and Havvatoglu, K. 2014: According to EUROPEP satisfaction scale family medicine family medicine satisfaction survey in Gumushane. Gumushane University Journal of Health Sciences 3 (4), 1067-78.

Carrière, G. 2004: Use of hospital emergency rooms. Health Reports 16 (1), 35-9.

Chan, B.T.B. and Ovens, H.J. 2002: Frequent users of emergency departments. Do they also use family physicians' services? Canadian Family Physician 48 (10), 1654-660.

Durand, A.C., Gentile, S., Gerbeaux, P., Alazia, M., Kiegel, P. and Luigi, S. 2011: Be careful with triage in emergency departments: interobserver agreement on 1578 patients in France. BMC Emergency Medicine 11, 10-11.

Dyrda, L. 2016: 25 facts and statistics on emergency departments in the US. Retrieved 31 October 2017 from https:/www.beckershospitalreview.com/hospital-manage ment-administration/25-facts-and-statistics-on-emergencydepartments-in-the-us.html.

Family Medicine Payment and Contract Regulation. Retrieved 31 October 2017 from http://www.mevzuat.gov.tr/MevzuatMetin/3.5.20101237.pdf.

Grumbach, K., Selby, J.V. and Damberg, C. 1999: Resolving the gatekeeping conundrum. What patients value in primary care and referrals to specialist. JAMA 282 (3), 261-66.

Hone, T., Gurol-Urganci, I., Millett, C., Basaran, B., Akdag, R. and Atun, R. 2017: Effect of primary health care reforms in Turkey on health service utilization and user satisfaction. Health Policy and Planning 32 (1), 57-67.

Hunt, K.A., Weber, E.J., Showstack, J.A., Colby, D.C. and Callaham, M.L. 2006: Characteristics of frequent users of emergency departments. Annals of Emergency Medicine 48 (1), 1-8.

Huntley, A., Lasserson, D., Wye, L., Morris, R., Checkland, K., England, H., Salibury, C. and Purdy, S. 2014: Which features of primary care affect unscheduled secondary care use? A systematic review. BMJ Open 4 (5), e004746.

Jelamschi, L. and De Ver Dye, T. 2009. Decline in under-5 mortality rate (U5MR) in Turkey: a case study. Ankara, Turkey: UNICEF.

Kringos, D., Boerma, W., Bourgueil, Y., Cartier, T., Dedeu, T., Hasvold, T., Hutchinson, A., Lember, M., Oleszczyk, M., Rotar Pavlic, D., Svab, I., Tedeschi, P., Wilm, S., Wilson, A., Windak, A., Van der Zee, J. and Groenewegen, P. 2013: The strength of primarycare in Europe: an international comparative study. British Journal of General Practice 63 (616), 742-50.

Lucas, H.R. and Sanford, M.S. 1998: An analysis of frequent users of emergency care at an urban university hospital. Annals of Emergency Medicine 32 (5), 563-68.

Mete, B., Pehlivan, E., Tekin, C., Nacar, E., Unver, E. and Baran, A. 2015: Satisfaction levels of the adults who benefit from the family medicine care in Malatya city center and the factors that affect it. Medicine Science 4 (4), 2721-731.

Ovens, H.J. and Chan, G.T. 2001: Heavy users of emergency services: a population-based review. Canadian Medical Association Journal 165 (8), 1049-50.

Shah, N.M. and Shah, M.A. 1994: Excessive utilization of hospital emergency services in pre-occupation Kuwait: trends and differentials. Medical Principals and Practice $3(3), 131$.

Starsfield, B., Shi, L. and Macinko, J. 2005: Contribution of primary care to health systems and health. The Milbank Quarterly 83 (3), 457-502.

Sun, B.C., Burstin, H.R. and Brennan, T.A. 2003: Predictors and outcomes of frequent emergency department users. Academic Emergency Medicine 10 (4), 320-28.

Turkish Ministry of Health, Annual Health Statistics. 2012-2014: Retrieved 31 October 2017 from www.saglik. gov.tr/TR/belge/1-2952/istatistik-yilliklari.html.

Ulker, V., Taskin, H.C., Yardimci, N., Hocagil, A.C. and Hocagil, H. 2017: Overcrowding is still a big problem for our emergency services, real disaster is in our emergency departments in Turkey. Prehospital and Disaster Medicine $32(1), 32$.

Ustu, Y. and Ugurlu, M. 2015: An analysis: is family medicine effective in our country? Ankara Medical Journal 15 (4), 244-48.

Vedsted, P., Sokolowski, I. and Heje, H.N. 2008: Data quality and confirmatory factor analysis of the Danish EUROPEP questionnaire on patient evaluation of general practice. Scandinavian Journal of Primary Health Care 26 (3), 174-80. 